\title{
Evapotranspiração potencial (ETp) e real (ETr) para diferentes usos da terra em uma bacia hidrográfica no sul do Brasil
}

A evapotranspiração pode ser determinada por métodos diretos ou indiretos, sendo que sua verificação é realizada pela comparação com os dados medidos. Este estudo teve por objetivo determinar a evapotranspiração real (ETr) para diferentes usos da terra que compõe a paisagem agrícola da bacia hidrográfica do Ribeirão Concórdia, comparando com a evapotranspiração potencial (ETp). Os usos da terra analisados foram: agricultura, floresta nativa, pastagem e reflorestamento. A ETp foi estimada pelo método Penman-Monteith (FAO-56) a partir de dados de uma estação meteorológica de superfície, e a ETr determinada por equipamentos instalados em campo, como lisímetros volumétricos, calhas de escoamento superficial e interceptadores de precipitação abaixo do dossel vegetativo nas áreas de mata nativa e reflorestamento. A precipitação na região se mostrou desuniforme e com valores acima da precipitação regional, em função das chuvas orográficas ocorridas na região. A área de floresta nativa teve um volume de interceptação de $11,2 \%$ maior que a área de reflorestamento. As chuvas de até $6,5 \mathrm{~mm}$ foram totalmente interceptadas pelo dossel vegetativo, enquanto no reflorestamento esse valor foi de apenas 2,1mm. O método de Penman-Monteith superestimou os valores de evapotranspiração em todos os usos da terra. O armazenamento de água no solo teve pouca variação em função do ciclo hidrológico ser um sistema dinâmico e entrar em equilíbrio ao longo do tempo. O escoamento superficial foi elevado nas áreas agrícola em função do manejo de solo adotado pelos produtores. O método do balanço hídrico se mostrou eficiente na determinação da ETr em uma escala de tempo decendial.

Palavras-chave: Uso do solo; Balanço hídrico; Evapotranspiração.

\section{Potential (ETp) and actual (ETr) evapotranspiration for different land uses in a watershed in southern Brazil}

\begin{abstract}
Evapotranspiration can be determined by direct or indirect methods, and its verification is performed by comparison with the measured data. This study aimed to determine the actual evapotranspiration (ETr) for different land uses that make up the agricultural landscape of the Ribeirão Concórdia watershed, compared with the potential evapotranspiration (ETp). The land uses analyzed were: agriculture, native forest, pasture and reforestation. ETp was estimated by the PenmanMonteith method (FAO-56) from surface weather station data, and ETr determined by field-installed equipment such as volumetric lysimeters, runoff gutters and below-canopy rainfall interceptors. vegetation in native forest and reforestation areas. The precipitation in the region was uneven and with values above the regional precipitation, due to the orographic rainfall occurred in the region. The native forest area had an interception volume of $11.2 \%$ greater than the reforestation area. Rainfalls up to $6.5 \mathrm{~mm}$ were totally intercepted by the vegetative canopy, while in reforestation this value was only $2.1 \mathrm{~mm}$. The PenmanMonteith method overestimated evapotranspiration values in all land uses. Soil water storage had little variation as the hydrological cycle is a dynamic system and comes into balance over time. The runoff was high in the agricultural areas due to the soil management adopted by the producers. The water balance method proved to be efficient in the determination of ETr in a decendial time scale.
\end{abstract}

Keywords: Use of the soil; Hydric balance; Evapotranspiration.

Topic: Engenharia Ambiental

Reviewed anonymously in the process of blind peer.
Received: 05/10/2018

Approved: 06/11/2018
Rafael Gotardo (iD)

Fundação Universidade Regional de Blumenau, Brasil http://lattes.cnpq.br/5161628431454077

http://orcid.org/0000-0003-1316-5181

rafael.piratuba@yahoo.com.br

Adilson Pinheiro

Fundação Universidade Regional de Blumenau, Brasil http://lattes.cnpq.br/7655568160453478

pinheiro@furb.br

Vander Kaufmann

Fundação Universidade Regional de Blumenau, Brasil

http://lattes.cnpq.br/1955590422141484

vanderkaufmann@gmail.com

DOI: 10.6008/CBPC2179-6858.2018.008.0010
Gustavo Antônio Piazza

Universidade Federal de Pelotas, Brasil

http://lattes.cnpq.br/7213274067945210 gustavoapiazza@gmail.com

Edson Torres

Fundação Universidade Regional de Blumenau, Brasil

http://lattes.cnpq.br/4733683099961781

ettotorres@gmail.com

\section{Referencing this:}

GOTARDO, R.; PINHEIRO, A.; KAUFMANN, V.; PIAZZA, G. A.; TORRES, E.. Evapotranspiração potencial (ETp) e real (ETr) para diferentes usos da terra em uma bacia hidrográfica no sul do Brasil. Revista IberoAmericana de Ciências Ambientais, v.9, n.8, p.109-126, 2018. DOI: http://doi.org/10.6008/CBPC2179-6858.2018.008.0010 


\section{INTRODUÇÃO}

Entender o ciclo hidrológico é uma forma de entender o regime hidrológico local, por meio do monitoramento de processos como infiltração, escoamento, armazenamento de água no solo e evapotranspiração (CARVALHO et al., 2008). Um processo complicado de mensurar é a evapotranspiração, que pode ser determina pela evapotranspiração potencial (ETp) ou pela evapotranspiração de referência ou real (ETr). A ETp é uma das formas de expressar a perda de água para a atmosfera em um local coberto de forma natural e com potencial matricial próximo a capacidade de campo (CAMARGO et al., 2000; REICHARDT et al., 2004). A ETr é a medida da perda de água em uma área nas condições climáticas e hídrica reinante (PEREIRA 1997), ou seja, a ETr sempre será menor ou igual à ETp (BERNARDO et al., 2008).

A estimativa da evapotranspiração pode ser realizada por métodos diretos ou indiretos (CUNHA et al., 2013). Os métodos indiretos são menos onerosos, e se baseiam em fórmulas matemáticas empíricas que combinam dados climatológicos medidos em estações meteorológicas (PEREIRA et al., 1997), dentre eles podemos citar: Thornthwaite (1948); Penman (1948); Priestley et al. (1972); Blaney-Criddle (1975); Doorenbos et al. (1977); Hargreaves (1977); Blaney-Criddle (1977); e Penman-Monteith FAO-56 (ALLEN et al., 1998). O uso de métodos baseados em equações com fundamentação física é a forma mais utilizada por pesquisadores, sendo o método de Penman-Monteith recomendado pela Organização das Nações Unidas para Alimentação e Agricultura (Food and Agriculture Organization - FAO).

Muitos autores, no entanto, consideram métodos indiretos extremamente limitados (HENRIQUE et al., 2007). Os métodos diretos são mais precisos, porém, mais difíceis de realizar, uma vez que envolvem custos de implementação e manutenção de equipamentos (SOUZA, 2011). Formas diretas de mensurar a evapotranspiração são: os tanques classe 'A'; lisímetros volumétricos ou de pesagem; e os tensiômetros de solo, sendo lisímetros os equipamentos mais eficientes na sua determinação (UNOLD et al., 2008; ESTEVES et al., 2010). Com os lisímetros é possível controlar entradas e saídas do sistema, e estabelecer a evapotranspiração real, permitindo assim o ajuste de modelos matemáticos (LOOS et al., 2007).

De acordo com Goulden et al. (2007), as diferentes técnicas de estimativa resultam em diferentes resultados de evapotranspiração para um mesmo local. Vepraskas et al. (2006) ressalta que diferenças na estimativa da evapotranspiração são uma das maiores fontes de incertezas nos estudos hidrológicos. Diferentes estudos também têm comparado medidas de evapotranspiração determinada por métodos diretos e indiretos, como Garcia et al. (2004), López-Urrea et al. (2006), Oliveira (2007), Barros et al. (2009), Unlu et al. (2010), Schrader et al. (2013) e Gebler et al. (2015).

Mesmo que na literatura existam diversas informações de evapotranspiração para diferentes regiões, a evapotranspiração é um processo local, que depende de taxas específicas para cada uso da terra. Neste sentido, este trabalho tem o objetivo de determinar a evapotranspiração real (ETr) pelo balanço hídrico para diferentes usos da terra que compõem a bacia hidrográfica do ribeirão Concórdia e comparar com a evapotranspiração potencial (ETp) determinada pelo método de Penman-Monteith (FAO-56). 


\section{METODOLOGIA}

O estudo foi desenvolvido na bacia hidrográfica do ribeirão Concórdia, no município de Lontras, estado de Santa Catariana (figura 1). A bacia hidrográfica tem uma variação de altitude de 340 a 900m, e uma área de drenagem de $30,7 \mathrm{~km}^{2}$. O clima da região é do tipo Cfa segundo Köeppen. O relevo é montanhoso nas encostas, mas conta com áreas alagáveis próximo ao exutório. A formação geológica da bacia é composta por suítes intrusivas graníticas do grupo Itararé, estando dentro do subgrupo da formação Rio do Sul. Esta formação é caracterizada pela presença de folhelhos, argilitos cinza escuro e diamictitos acinzentados. Os solos são Cambissolos (66,17\%), Argissolos (32,91\%) e Gleissolos (0,92\%).

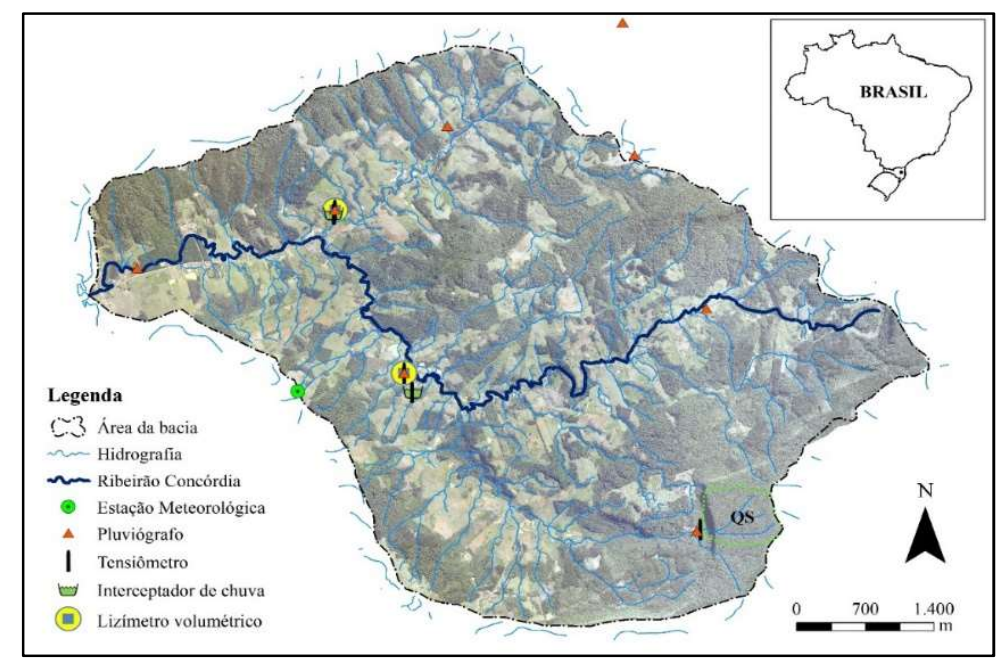

Figura 1: Localização da bacia e dos pontos de monitoramento hidrológico.

A classificação do uso da terra, gerada com a base a cartográfica da Secretaria de Desenvolvimento Sustentável (SDS-SC) e por Sistema de Informação Geográfica (ArcGIS 10.3), mostrou que a bacia hidrográfica é em sua grande parte composta por floresta nativa $(45,1 \%), 17,5 \%$ é referente a pastagem perene, $15,7 \%$ de agricultura geral; $14,4 \%$ de reflorestamento de pinus spp. e eucalyptus ssp.; $2,3 \%$ de áreas em regeneração florestal; $1,1 \%$ de água; e 3,9\% de outros (área construída).

O trabalho monitorou os quatro principais usos da terra que compõe a paisagem da bacia. Uma área de agricultura com 0,5 ha localizada na latitude $27^{\circ} 10^{\prime} 23.1^{\prime \prime}$ S e longitude $49^{\circ} 30^{\prime} 06.4^{\prime \prime} \mathrm{O}$, a uma altitude de $354 \mathrm{~m}$. Neste local é realizado o cultivo anual de milho e feijão como culturas de verão e aveia preta no inverno. O solo da área é Cambissolo Háplico alumínico típico de textura franco argilosa com 26,9\% areia, $37,2 \%$ de silte e $35,9 \%$ argila, com relevo suave-ondulado onde a declividade média varia de 3 a $8 \%$. O manejo do solo adotado é o convencional com uso de aração e gradagem, no qual proporciona o revolvimento contínuo e intenso do solo. Uma área de reflorestamento com relevo ondulado e declividade média que varia em torno de 13 a $20 \%$.

A área de reflorestamento possui 0,5ha de cultivo de eucalipto (Eucalyptus grandis) com seis anos de idade, plantados em um espaçamento de 3,0 ×2,0m, totalizando 830 plantas por hectare. A área escolhida está localizada na latitude $27^{\circ} 10^{\prime} 24.6^{\prime \prime} \mathrm{S}$ e na longitude $49^{\circ} 30^{\prime} 06.6^{\prime \prime} \mathrm{O}$, a uma altitude de $357 \mathrm{~m}$. O solo desta área é Cambissolo Háplico alumínico típico de textura argilosa com 21,2\% areia, 35,4\% de silte e 43,5\% 
argila. Uma área de pastagem de 3,0ha na latitude $27^{\circ} 10^{\prime} 23.0^{\prime \prime} \mathrm{S}$ e longitude $49^{\circ} 30^{\prime} 06.2^{\prime \prime} \mathrm{O}$, a $360 \mathrm{~m}$ de altitude.

O solo desta área é Cambissolo Háplico alumínico típico de textura franco argilosa com 22,4\% areia, $44,5 \%$ de silte e $33,1 \%$ argila, com uma declividade média que varia de 13 a $20 \%$, sendo o relevo classificado como ondulado. A área é composta predominantemente pela grama batatais (Paspalum notatum), mas também são encontradas outras espécies como grama forquilha (Paspalumnotatum fluegge), capim caninha (Andropogon lateralis) e grama missioneira (Axonopus pressus). Nesta área são adotados somente manejo de roçadas e aplicação de herbicidas. Os animais são mantidos permanentemente na área, mantendo assim a vegetação sempre baixa.

E uma área de floresta nativa, pertencente a tipologia da floresta Ombrófila Densa do Bioma Mata Atlântica com 4,0ha em estágio avançado de regeneração. A área está localizada uma latitude $27^{\circ} 11^{\prime} 25.9^{\prime \prime}$ e longitude $49^{\circ} 29^{\prime} 37.1^{\prime \prime}$ e uma altitude $774 \mathrm{~m}$. O solo da área é Cambissolo Háplico alumínico típico de textura argilosa com $39,8 \%$ de areia, $38,9 \%$ de silte e $21,3 \%$ de argila. O relevo é considerado montanhoso devido a sua declividade média estar acima dos $45 \%$, e com presença de uma escarpa de alta declividade em sua face leste. As concentrações de silte, argila e areia e textura para cada usos da terra abordados neste estudo estão expressos na tabela 1.

Tabela 1: Análise granulométrica dos solos estudados na bacia.

\begin{tabular}{|c|c|c|c|c|}
\hline Uso & Areia & Silte & Argila & Textura \\
\hline & \multicolumn{3}{|c|}{ 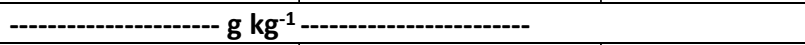 } & \\
\hline Agricultura & 268,71 & 372,29 & 359,00 & Franco argiloso \\
\hline Pastagem & 223,90 & 445,38 & 330,72 & Franco argilosc \\
\hline Reflorestamento & 212,42 & 354,08 & 433,50 & Argiloso \\
\hline Floresta nativa & 115,65 & 371,35 & 513,00 & Argiloso \\
\hline
\end{tabular}

Os dados meteorológicos foram obtidos em uma estação meteorológica de superfície, que segue os padrões da Organização Mundial de Meteorologia (OMM). A coleta de dados foi realizada em uma frequência horária e sub-horária e foram armazenados em datalogger. Os equipamentos que compõe a estação são: pluviógrafo, pluviômetro de pesagem, termo higrômetro (umidade e temperatura do ar), sensor de molhamento foliar, piranômetro, barômetro, anemômetro ultrassônico e termômetro de solo.

Com o objetivo de uniformizar os dados e aumentar a precisão, a precipitação também foi monitorada em intervalos de 5 minutos de forma distribuída ao longa da bacia hidrográfica por oito pluviógrafos do tipo báscula com sistema de compensação. A altura padrão de instalação dos pluviógrafos foi padronizado em $1,5 \mathrm{~m}$ do solo. Os dados foram baixados dos dataloggers quinzenalmente, e as falhas consistidas através do método das razões dos valores normais, ou método das médias ponderadas (PAULHUS et al., 1952). A precipitação média da bacia foi determinada através do método de Thiessen, que calcula a média ponderada da precipitação em relação a área de influência de cada pluviógrafo.

Foi realizado também o monitoramento da interceptação da precipitação pela cobertura vegetal nas áreas de floresta nativa e reflorestamento, sendo definida como o total precipitado menos a água retida pelo dossel das plantas. A interceptação tem grande significância dentro dos estudos hidrológicos, pois representa 
uma parcela significativa de água que muitas vezes não atinge o solo e fica disponível para a evaporação (SARI et al., 2016). Inúmeros estudos têm quantificado as perdas por intercepção vegetal, no qual confirmam perdas de até $25 \%$ da precipitação em áreas de floresta e reflorestamento, vindo a gerar erros significativos na estimativa do balanço hídrico (ALMEIDA et al., 2003; LANE et al., 2004; ALVES et al., 2007; MOURA et al., 2009; MOURA et al., 2012; LIVESLEY et al., 2014).

O objetivo de determinar a porcentagem de precipitação interceptada pelo dossel vegetativo foi incluí-lo no cálculo e aumentar a precisão da estimativa do balanço hídrico. Os interceptômetros foram desenvolvidos no laboratório de hidrologia da FURB e constituem de uma espécie de funil metálico de $40 \mathrm{x}$ $40 \mathrm{~cm}$, totalizando uma abertura de coleta de $160 \mathrm{~cm}^{2}$. A precipitação coletada era direcionada através de um encanamento a bombonas de polietileno e a cada quinze dias a precipitação acumulada foi medida por meio de uma proveta e os dados transformados em lâmina de água precipitada através da área de coleta dos interceptômetros.

Com finalidade de evitar o entupimento dos interceptômetros por folhas e galhos foi instalada uma tela de entrada de cada um deles. O escoamento lateral ocorrido através do tronco das árvores foi desconsiderado, visto que diversos autores relatam as dificuldades na quantificação e a baixa significância dentro dos componentes hidrológicos, onde o erro pode ser maior que a própria estimativa (CUARTAS et al., 2007; SOUZA et al., 2011).

Nas áreas de pastagem e agricultura a quantificação dos componentes hidrológicos foi por meio dos lisímetros volumétricos. Os lisímetros são equipamentos que reproduzem as condições naturais do uso da terra, e consistem em tanques de acrílico enterrados no solo. Os equipamentos utilizados são do tipo volumétrico contendo uma amostra de solo indeformada de $1 \mathrm{~m}^{3}$. Estes equipamentos são constituídos de duas caixas de acrílico com $12 \mathrm{~mm}$ de espessura, sendo uma caixa com um volume de $1 \mathrm{~m}^{3}$, para coleta da amostra de solo e outra com um volume de $0,10 \mathrm{~m}^{3}$ para confecção da base.

A base do lisímetro é onde fica o sistema de coleta do escoamento de drenagem pela amostra de solo. O escoamento flui por um sistema de drenagem confeccionada por brita e bidim e é direcionado por meio de encanamentos de PVC a um sistema eletrônico de medição por báscula e os dados armazenamento em um datalogger em intervalos de tempo de 5 minutos.

Para a área de reflorestamento, a quantificação do escoamento superficial foi realizada por uma parcela padrão de Wischmeier et al. (1978), enquanto a drenagem foi calculada pelo método do perfil instantâneo. A parcela constitui de uma área de $20 \mathrm{~m}^{2}$, isolada com chapas galvanizadas de $28 \mathrm{~cm}$ de largura, sendo que $5 \mathrm{~cm}$ foram enterrados no solo. A parte frontal é constituída de uma calha em forma de um triângulo com uma área de $3,75 \mathrm{~m}^{2}$ também em material galvanizado coberta para coletar o escoamento gerado na parcela, que é conduzido por encanamento a uma caixa plástica de $28 \times 40$ × $20 \mathrm{~cm}$, tendo a função de um poço tranquilizador e de retenção de sedimentos.

A água no interior do recipiente permanece em um nível constante e fechada para evitar perdas por evaporação. Na sequência o escoamento era direcionado por gravidade a um pluviógrafo de báscula, onde o volume era medido. Neste sistema, os dados são gerados através de um pulso elétrico, onde cada pulso é 
equivalente a 4,76mL. Assim, o total de pulsos significa o volume do escoamento coletado, que dividido pela área da parcela resulta no total de milímetros escoado. Os dados gerados eram armazenados em um datalogger NOVUS LOGBOX ${ }^{\circledR}$ em intervalos de 15 minutos.

A drenagem profunda na área de reflorestamento foi realizada através do Método do Perfil Instantâneo - MPI (LIBARDI, 2005). A escolha deste método foi adotada pelo fato de ser o único que permite obter, in situ a relação entre a condutividade hidráulica $K$ e a umidade volumétrica $\vartheta$ (curva $K(\vartheta))$. $O$ método desenvolvido por Hillel et al. (1972) permite encontrar a função $K(\vartheta)$ no campo a partir da evolução temporal do teor de água no solo em um determinado período, por meio da drenagem interna no qual a evaporação é anulada. Este método é utilizado em meios não-saturados tendo como base a equação de Richards para um conteúdo de água e potencial total de água no solo em drenagem vertical após a precipitação (PAIGE et al., 1993).

A variação do teor de água no solo em diferentes profundidades foi obtida por meio do monitoramento da umidade do solo com uso de um TDR e do potencial matricial do solo determinado tensiômetros em profundidades conhecidas. Para a determinação da condutividade hidráulica do solo utilizou-se o MPI utilizando a quantificação da equação de Richards na direção vertical, segundo a Equação de Richards para fluxo transitório, que é $\frac{\partial \theta}{\partial t}=\frac{\partial}{\partial z}\left(K(\theta, \Psi m) \frac{\partial \Psi t}{\partial z}\right)$, considerando-se que $\vartheta$ é a umidade volumétrica $\left(\mathrm{cm}^{3} \mathrm{~cm}^{-3}\right) ; t$ o tempo $(\mathrm{h}) ; K\left(\vartheta, \Psi_{m}\right)$ a condutividade hidráulica $\left(\mathrm{cm} \mathrm{h}^{-1}\right) ; \Psi_{m}$ o potencial matricial da água $(\mathrm{cm})$; e z a coordenada da posição vertical $(0-70 \mathrm{~cm})$.

As zonas de fluxo ascendente da parte superior do perfil e do fluxo descendente na parte inferior são separadas por um plano de fluxo zero (PFZ). Assim, integrou-se- a equação de Richards considerando a profundidade entre o plano de fluxo zero e a profundidade de $70 \mathrm{~cm}$, seguindo: $Z=Z_{P F Z} ; \quad t>$ $0 ; \quad q=0$; e $Z=Z ; \quad t<0 ; \quad q=q_{Z}$, considerado $q$ o fluxo; e $q z$ o fluxo na profundidade 70 cm. E assim, temos: $\int_{Z_{P F Z}}^{Z} \frac{\partial \theta}{\partial t} d z=K(\theta, \Psi m) \frac{\partial \Psi t}{\partial z} \mid \frac{0}{z}=q z$. Rearranjando a equação, temos: $K(\theta, \Psi m)_{z}=$ $\frac{q_{Z}}{\frac{\partial \Psi t}{\partial z} \mid \frac{0}{z}}=\frac{\int_{Z_{P F Z}}^{Z} \frac{\partial \theta}{\partial t} d z}{\frac{\partial \Psi t}{\partial z} \mid \frac{0}{z}}=\frac{\frac{\partial h_{P F Z-Z}}{\partial t}}{\frac{\partial \Psi t}{\partial z} \mid \frac{0}{z}}$, onde: $h_{z P F Z-z}$ é o armazenamento água no solo $\left(\mathrm{cm}^{3} \mathrm{~cm}^{-2}\right)$; e $z$ é a profundidade $70 \mathrm{~cm}$.

Os tensiômetros utilizados neste estudo são da marca UMS ${ }^{\circledast}$ modelo $T 4$ e estão instalados em três profundidades do solo $(10,30$ e $70 \mathrm{~cm})$. Este equipamento possui uma faixa de medição da tensão matricial do solo que varia entre $+100 \mathrm{hPa}$ e $-850 \mathrm{hPa}$ com uma precisão de $\pm 5 \mathrm{hPa}$. Os tensiômetros foram instalados com o auxílio de um trado em um ângulo variando entre $20^{\circ}$ e $70^{\circ}$. Os registros dos dados foram obtidos em hectopascal ( $\mathrm{hPa}$ ) em intervalos de tempo de 15 minutos e armazenados em um datalogger Delta Link ${ }^{\circledR}$.

A umidade do solo em cada um dos usos foi monitorada com o objetivo de elaborar as curvas de retenção diretamente no campo utilizando a umidade do solo em relação a tensão levantada nos tensiometros. O TDR utilizado é um sensor da marca TRIME ${ }^{\circledR}$-PICO IPH desenvolvido pela empresa alemã IMKO MicromodultechnikGmbH, também chamado de TRIME-TDR (Time Domain Reflectometry). Este 
equipamento possibilidade determinar a umidade em perfis verticais de solo de forma contínua e sem alterar a estrutura do solo.

Para isso são instalados no solo tubos de acesso chamados TECANAT (44,3mm de diâmetro externo, $42,0 \mathrm{~mm}$ de diâmetro interno e $1,0 \mathrm{~m}$ de comprimento) por meio de um conjunto de equipamentos especialmente desenvolvidos. A sonda consiste em um corpo cilíndrico de PVC e metal com 166mm de comprimento e $32 \mathrm{~mm}$ de diâmetro, o que possibilidade sua inserção nos tubos. No interior do tubo a sonda gera um pulso de alta frequência que se propaga ao longo da haste de metal, no qual é dependente da constante dielétrica do solo. Assim, gera um campo eletromagnético ao redor da sonda. Ao final das placas, o impulso é refletido de volta a sua origem. Então, o tempo percorrido pelo pulso neste caminho permite a determinação da velocidade de sua propagação que é depende da umidade do solo.

A quantificação dos componentes hidrológicos em áreas florestadas é complexa e de difícil execução tendo em vista o sistema radicular e da projeção das copas dos indivíduos arbóreos. Por isso, a determinação da ETr para floresta nativa foi realizada por meio do balanço hídrico em uma das sub-bacias que compõe a bacia do ribeirão Concórdia, denominada 'sub-bacia Qs'. A sub-bacia Qs é uma bacia hidrográfica com $0,42 \mathrm{~km}^{2}$ e $100 \%$ coberta por floresta nativa em estágio avançado de regeneração.

Desta forma, foi considerado que a entrada de água é dada pela precipitação e a saída ocorre através da vazão do rio. Além disso, considerou-se que as perdas de água ao longo do tempo se equivaleram, ou seja, considerou-se que, em longos intervalos de tempo, as variações de armazenamento da água podem ser desprezadas, considerando que todos os fluxos de entrada e saída estão sob controle (COLLISCHONN et al., 2008).

Para a realização do balanço hídrico na sub-bacia Qs foi monitorado a vazão do córrego por meio de uma calha Parshall para vazões baixas (até $37 \mathrm{~cm}$ ) e a cota através de um linígrafo para vazões altas (acima de $37 \mathrm{~cm}$ ). A calha Parshall utilizada é fabricada fibra de vidro com capacidade $60 \mathrm{~m}^{3} \mathrm{~h}^{-1}$, e a leitura é realizada em uma régua graduada calibrada $\mathrm{em}^{3}$ na lateral do próprio equipamento. Mas com o objetivo de realizar o monitoramento contínuo e aumentar a precisão em cotas baixas, foi instalado um sensor hidrostático lateralmente a calha por meio de um tubo de PCV, no qual o sensor permaneceu com o mesmo nível de água do contido na garganta da calha.

O sensor utilizado é da marca GE Measurement\&Sensing ${ }^{\circledR}$ da série PTX/PDCR 1730, com intervalos de pressão de $0,75 \mathrm{mH}_{2} \mathrm{O}$ a $600 \mathrm{mH}_{2} \mathrm{O}$ e exatidão de $\pm 0,06 \%$. Além da calha Parshall utilizado para determinação de vazões com cotas de até $37 \mathrm{~cm}$, foi instalado um sensor de nível tipo boia (linígrafo), usado nas correções das medidas da calha Parshall e nos extravasamentos (ultrapassa $60 \mathrm{~m}^{3} \mathrm{~s}$ ou $37 \mathrm{~cm}$ da cota da calha). Desta forma foi possível monitorar as vazões máximas e mínimas com boa precisão, até $37 \mathrm{~cm}$ pela calha Parshall, e acima de $37 \mathrm{~cm}$ pelo linígrafo. As curvas chave foram elaboradas através de medições de vazão realizadas em diferentes cotas com auxílio de um molinete OTT Hydromet ${ }^{\circledast}$ modelo $C 31$, equipado com um contador de giro $O T T Z 400^{\circledR}$.

Os cálculos de evapotranspiração para as áreas de reflorestamento, floresta e pastagem foram realizados considerando apenas uma cultura. Na área agrícola como o cultivo é dado por culturas anuais que 
mudam ao longo do ano, o cálculo de evapotranspiração foi realizado considerando o ciclo de cada cultura. Desta forma, o balanço hídrico permitiu acompanhar e entender comportamento da água no sistema. Para este estudo a equação do balanço hídrico foi modificada para a determinação da ETr seguindo a equação de Lima (2006), que é a Equação do balanço hídrico modificada para determinação da ETr: $E T r=P-E s-$ $D p \mp \triangle A$, sendo que ETr é a evapotranspiração real $\left(\mathrm{mm} \mathrm{dia}^{-1}\right)$; $\mathrm{P}$ é a precipitação pluvial ( $\left.\mathrm{mm} \mathrm{dia}^{-1}\right)$; Es é o escoamento superficial $\left(\mathrm{mm} \mathrm{dia}^{-1}\right)$; $\mathrm{Dp}$ é a drenagem profunda $\left(\mathrm{mm} \mathrm{dia}^{-1}\right)$; e $\Delta \mathrm{A}$ é a variação do armazenamento de água no perfil do solo $\left(\mathrm{mm} \mathrm{dia}^{-1}\right)$.

Considerando que o objetivo do balanço neste estudo era a determinação da $E T r$, o armazenamento de água no solo foi calculado pela regra do trapézio. Esta equação considera que o conteúdo de água no solo varia linearmente com a profundidade entre dois pontos consecutivos, desde a superfície $Z_{0}(Z=0)$ até a profundidade de interesse $Z_{L}(Z=L)$. Neste caso, é realizada a integração entre $Z_{0}$ e $Z_{L}$, considerando a primeira e a última camada $\left({ }_{2}^{1 /} \Delta Z\right)$. Assim considera-se que a primeira medida não é realizada a $Z_{0}$ e nem a última em $Z_{L}$. Para melhor entender a equação do trapézio é apresentada a Regra do trapézio para $n$ incrementos iguais em $n$ profundidades, que é $A_{S}=\int_{0}^{L} \theta(Z) d Z=\left[0,50\left(Z_{0}+\sum_{i=1}^{n-1} \theta\left(Z_{i}\right)+0,50\left(Z_{n}\right)\right]\right.$, na qual se considera $\triangle \mathrm{A}$ a variação do armazenamento de água no solo $(\mathrm{mm}) ; \theta$ a umidade volumétrica do solo $\left(\mathrm{m}^{3} \mathrm{~m}^{-3}\right)$; e $\mathrm{Z}$ a espessura da camada de solo $(\mathrm{cm})$.

A variação do armazenamento de água no perfil de solo $(\Delta A)$ foi determinada pela diferença dos valores de umidade volumétrica obtidos no perfil nos tempos inicial e final de cada período considerado (LIBARDI, 2005). Esta variação pode ser positiva, com o aporte de água no perfil ou negativa com o déficit de água. Assim, a variação de armazenamento foi calculada pela Variação de armazenamento de água no solo, que é: $\triangle A=\left(\theta_{f}-\theta_{i}\right) \quad h=\left(\theta_{f}-\theta_{i}\right)$, tendo $\triangle \mathrm{A}$ como a variação de armazenamento (mm); $\theta_{\mathrm{f}} \mathrm{o}$ armazenamento final (mm); e $\theta_{i} \mathrm{o}$ armazenamento inicial $(\mathrm{mm})$.

A ETp representa a perda de água da superfície terrestre vegetada em crescimento ativo e sem restrição hídrica, ou seja, a ETp depende das variáveis meteorológicas do clima e fisiológicas das plantas. Ela foi estimada na escala diária ( $\mathrm{mm} \mathrm{dia}^{-1}$ ) pelo método de Penman-Monteith proposto por Allen et al. (1989) seguindo o manual de padronização da equação de referência da evapotranspiração estabelecida pela ASCE - Sociedade Americana de Engenheiros Civis (ASCE-EWRI, 2005) e após juntado em dados decendiais e mensais. A equação de Penman-Monteith padrão FAO-56 é dada pelo Método de Penman-Monteith para determinação da ETp: ETp $=\frac{0,408 \times \Delta \times\left(R_{n}-G\right)+\gamma \times \frac{C_{n}}{T+273} \times U_{2} \times\left(e_{s}-e_{a}\right)}{\Delta+\gamma \times\left(1+C_{d} \times u_{2}\right)}$.

Nessa equação, ETp é evapotranspiração de referência para culturas baixas ou altas $\left(m m\right.$ dia $\left.^{-1}\right) ; R_{n}$ é o balanço de radiação líquida na superfície da cultura ( $\mathrm{MJ} \mathrm{m}^{-2}$ dia $^{-1}$ ); G é a densidade fluxo de calor na superfície do solo ( $\left.\mathrm{MJ} \mathrm{m}^{-2} \mathrm{dia}^{-1}\right)$; T é a temperatura média diária do $\operatorname{ar}\left({ }^{\circ} \mathrm{C}\right) ; \mathrm{U}_{2}$ a velocidade média diária do vento $\left(\mathrm{m} \mathrm{s}^{-1}\right) ; \mathrm{e}_{\mathrm{s}}$ a pressão saturação de vapor média diária $(\mathrm{kPa}) ; \mathrm{e}_{\mathrm{a}}$ a média da pressão de saturação de vapor $(\mathrm{kPa}) ; \mathrm{e}_{\mathrm{s}}-\mathrm{e}_{\mathrm{a}}$ o déficit pressão de saturação de vapor ( $\left.\mathrm{kPa}\right) ; \Delta$ a inclinação da curva de pressão de vapor de saturação $\left(\mathrm{kPa}{ }^{\circ} \mathrm{C}^{-1}\right) ; \gamma$ a constante psicométrica $\left(\mathrm{kPa}{ }^{\circ} \mathrm{C}^{-1}\right) ; \mathrm{Cn}$ é a constante para o tipo de cultura de referência e o intervalo de tempo $\left(\mathrm{K} \mathrm{mm} \mathrm{s}^{-3} \mathrm{Mg}^{-1} \mathrm{dia}^{-1}\right)$; $\mathrm{C}$ é a constante do denominador para o tipo de 
cultura de referência e o intervalo de tempo $\left(\mathrm{s} \mathrm{m}^{-1}\right)$. Para o coeficiente 0,408 as unidades de medidas são $\mathrm{m}^{2}$ $\mathrm{mm} \mathrm{MJ} \mathrm{J}^{-1}$.

Os valores utilizados nas constantes do denominador $(C d)$ e do numerador $(C n)$ variam de acordo com a escala de análise sendo que o $C d$ e $C n$ varia também de acordo com a radiação líquida. Neste estudo os valores tiveram como base o manual de padronização da equação de referência da evapotranspiração estabelecida pela ASCE para culturas altas e baixas em uma escala de cálculo horária. Os valores das constantes do denominador $(C d)$ e a constante do numerador $(C n)$ estão descritas na tabela 2 , considerando que neste trabalho o cálculo foi realizado em uma escala diária.

Tabela 2: Valores das constantes $C d$ e $C n$, para a equação de Penman-Monteith em função do espaço de tempo, da radiação líquida na superfície vegetal e da altura da cultura.

\begin{tabular}{|c|c|c|c|c|c|c|}
\hline \multirow[t]{2}{*}{ Etapa de tempo do cálculo } & \multicolumn{2}{|c|}{$\begin{array}{c}\text { Cultura baixa } \\
\text { ET }_{\text {os }}\end{array}$} & \multicolumn{2}{|c|}{$\begin{array}{c}\text { Cultura alta } \\
E_{\text {rs }}\end{array}$} & \multirow[t]{2}{*}{ Unidades para $\mathrm{ET}_{\mathrm{os}}, \mathrm{ET}_{\mathrm{rs}}$} & \multirow[t]{2}{*}{ Unidades para Rn, G } \\
\hline & $C n$ & $C d$ & $C n$ & $C d$ & & \\
\hline Diário & 900 & 0.34 & 1600 & 0.38 & $\mathrm{~mm} \mathrm{~d}^{-1}$ & $M J m^{-2} d^{-1}$ \\
\hline Horário durante o dia & 37 & 0.24 & 66 & 0.25 & $\mathrm{~mm} \mathrm{~h}^{-1}$ & $M J m^{-2} h^{-1}$ \\
\hline Horário durante a noite & 37 & 0.96 & 66 & 1.7 & $\mathrm{~mm} \mathrm{~h}^{-1}$ & MJ $m^{-2} h^{-1}$ \\
\hline
\end{tabular}

Fonte: ASCE-EWRI (2005).

A altitude e a latitude específica foram levadas em consideração no cálculo, utilizados na determinação da radiação solar de dias claros (Rso), que compõem o cálculo da radiação líquida (Rn) na equação de Penman-Monteith. Outro fator preponderante é o chamado albedo que representa a razão entre a radiação solar refletida pela superfície e a radiação solar incidente. Neste estudo o albedo das culturas utilizados teve como base estudos específicos, como na tabela 3.

Tabela 3: Valores de albedo adotado para os cálculos de evapotranspiração.

\begin{tabular}{|l|l|l|}
\hline Cultura & Albedo & Referência \\
\hline Milho & 0,20 & Rodrigues et al. (2012) \\
\hline Feijão & 0,14 & Mota et al. (1991) \\
\hline Aveia & 0,18 & Mota et al. (1991) \\
\hline Pastagem & 0,20 & Randow et al. (2004) \\
\hline Reflorestamento & 0,10 & Tasumi et al. (2008) \\
\hline Floresta & 0,11 & Tasumi et al. (2008) \\
\hline
\end{tabular}

A análise estatística foi por meio da análise básica (médias, máximas, mínimas, desvio padrão) e análise de variância ANOVA (two-way). A comparação das médias foi realizada pelo Teste de Tukey a 5\% de probabilidade. Com o objetivo de comparar os dois métodos de determinação da evapotranspiração foi realizada a análise de correlação de Pearson $\left(R^{2}\right)$ no qual expressa uma medida numérica do grau da relação encontrada entre as variáveis. Os dados foram organizados foram organizados em planilha Excel e analisados no software Statistica.

\section{RESULTADO E DISCUSSÃO}

Na caracterização da precipitação dos diferentes usos da terra, os registros diários foram totalizados na escala mensal e a série histórica foi definida por quatro anos hidrológicos de 2013 a 2016. Os dados foram 
comparados com a precipitação média ocorrida na região do vale do rio Itajaí, conforme Figura 2. Pode-se observar que a distribuição da precipitação foi diferente da média regional, com valores mensais superiores.

A precipitação média na bacia do ribeirão Concórdia foi de $2.453,8 \mathrm{~mm}$ e a média regional de $1.665,1 \mathrm{~mm}$, ou seja, a precipitação no interior da bacia foi 32\% superior à média da região. Além dos anos de estudos terem maiores volumes de precipitação, a diferença está relacionada com a escala da bacia. A Bacia do ribeirão Concórdia é uma bacia fácil de monitorar e coletar eventos relacionados a ela, quando comparado com dados de bacias hidrográficas maiores e distante das áreas de cabeceira.

A bacia hidrográfica do Ribeirão Concórdia sofre mais com chuvas orográficas, principalmente na sub-bacia Qs que possui apenas $0,42 \mathrm{~km}^{2}$, localizada em meio a escarpas montanhosas íngremes. Normalmente esses locais possuem mais vegetação e consequentemente níveis mais elevados de precipitação. Segundo Silva et al. (2012) as chuvas orográficas são causadas pela ascensão do ar úmido e quente sobre regiões com grandes variações de altitude.

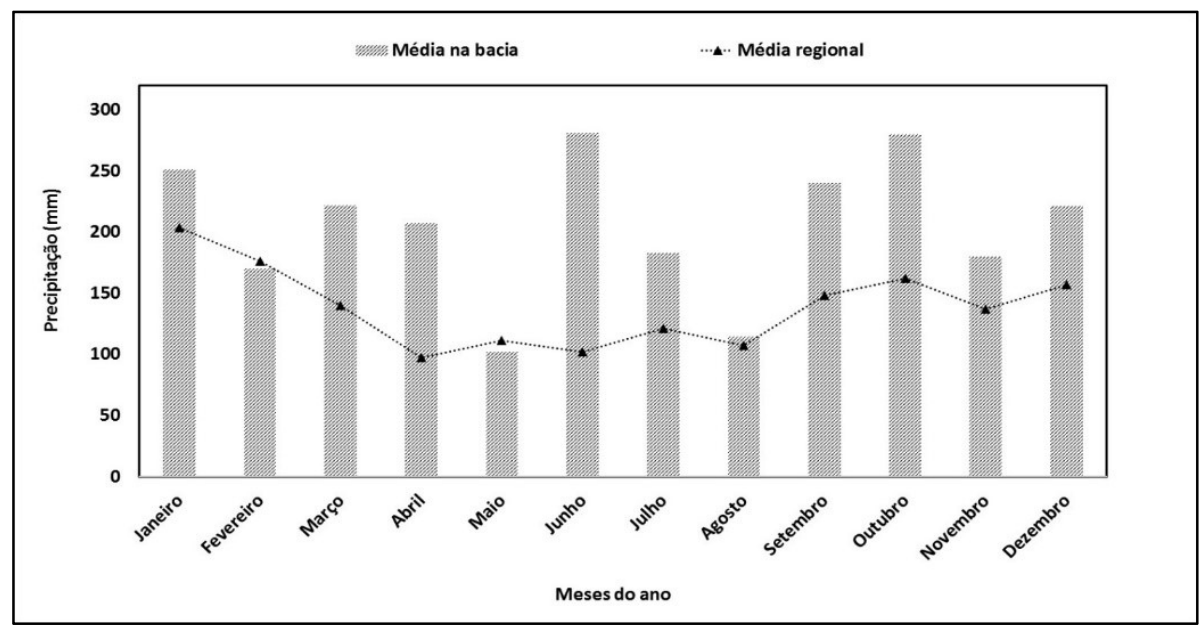

Figura 2: Distribuição anual da precipitação mensal nos diferentes usos da terra e a média da precipitação regional ocorrida entre os anos de 2013 e 2016.

As alturas de precipitação tanto na bacia hidrográfica monitorada como na região foram distribuídas de forma irregular ao longo do ano, com maior altura de chuva nos meses de junho $(279,1 \mathrm{~mm})$ seguido pelo mês de outubro $(279,7 \mathrm{~mm})$ e por janeiro $(251,1 \mathrm{~mm})$. A menor altura ocorreu em maio $(103,3 \mathrm{~mm})$ padrão este já encontrado por Gotardo et al. (2018) na região. Vale destacar que os meses de fevereiro, maio e agosto apresentaram médias mensais próximas a da média da região. 0 mês de junho apresentou a maior diferença com a precipitação regional, com quase $178,8 \mathrm{~mm}$ a mais no interior da bacia. A distribuição irregular das chuvas também foi observada por Piazza et al. (2017), que também associou as chuvas orográficas da região que tendem a elevar o acumulado de precipitações em zonas de encostas de morros.

A avaliação da interceptação pelo dossel vegetativo realizada nas áreas de floresta nativa e reflorestamento, foi apresentada na tabela 4 para o período de 2015 a 2016. A precipitação média anual para o período (2015-2016) foi de $2.186,5 \mathrm{~mm}$ para a floresta nativa e de $2.280,1 \mathrm{~mm}$ para a área de reflorestamento, sendo que os valores de interceptação média para o mesmo período foram de 1.307,9mm na floresta nativa $(46,8 \%$ de interceptação) e de $1.421,1 \mathrm{~mm}$ para o reflorestamento $(36,1 \%$ do total precipitado). 
Este resultado está de acordo com os valores de interceptação encontrados na literatura, como Livesley et al. (2014) que obteve interceptação entre 29 e 44\% em áreas de eucalipto variando em relação a densidade do dossel vegetativo. Em florestas naturais Dijk et al. (2015) encontrou valores de 10 a 50\% de interceptação para com a precipitação total. E Thomaz (2005), em florestas nativas, encontrou valores um pouco superiores, com até $52,4 \%$ do total precipitado.

Tabela 4. Valores anuais de interceptação para as áreas de floresta nativa e reflorestamento (2015-2016).

\begin{tabular}{|c|c|c|c|c|c|c|c|}
\hline \multicolumn{2}{|l|}{ Variável } & \multicolumn{3}{|c|}{ Floresta nativa } & \multicolumn{3}{|c|}{ Reflorestamento } \\
\hline Precipitação externa & \multirow{3}{*}{$\mathrm{mm}$} & $2.186,5$ & \pm & 69,6 & $2.280,1$ & \pm & 72,3 \\
\hline Precipitação interna & & 878,6 & \pm & 25,7 & 859,1 & \pm & 45,1 \\
\hline Interceptação & & $1.307,9$ & \pm & 28,6 & $1.421,0$ & \pm & 32,9 \\
\hline Interceptado & \multirow{2}{*}{$\%$} & 46,8 & \pm & 17,7 & 36,1 & \pm & 15,3 \\
\hline Efetivo & & 53,2 & & - & 63,9 & & - \\
\hline
\end{tabular}

Com base na regressão linear do precipitado interno e externo foi determinado que em áreas de floresta nativa chuvas de até $6,5 \mathrm{~mm}$ ficam totalmente interceptadas, enquanto no reflorestamento chuvas de até 2,1mm são totalmente interceptadas (figura 3). Moura et al. (2009) determinou em um fragmento de floresta da Mata Atlântica que chuvas de até $4,9 \mathrm{~mm}$ eram totalmente interceptadas. E Pereira et al. (2016) na quantificação da chuva oculta em uma floresta da Serra do Mar, determinou que chuvas de até 7,5 mm são totalmente interceptadas. Livesley et al. (2014), em um estudo sobre interceptação da precipitação pelo eucalipto, obteve valores de chuvas totalmente interceptadas de 3,9 e 3,0mm as espécies Eucalyptus nicholii e Eucalyptus saligna, respectivamente. Lima (2008) explica que estes valores tendem a ser diferentes pois a capacidade de armazenamento do dossel é influenciada pela espécie de cada região.

Na figura 3A é possível verificar que na área de floresta nativa precipitação interna mesmo com chuvas de maiores volumes o atravessamento das gotas é baixo, contrário do reflorestamento (Figura 3B), onde o atravessamento das gotas é maior. Em ambas as estimativas, o coeficiente de determinação $\left(R^{2}\right)$ foi alto, com $92 \%$ na floresta nativa e $89 \%$ no reflorestamento. Estes resultados são semelhantes aos encontrados por Sari et al. (2016), que obteve uma relação parecida para uma área de Mata Atlântica e de reflorestamento de eucalipto.

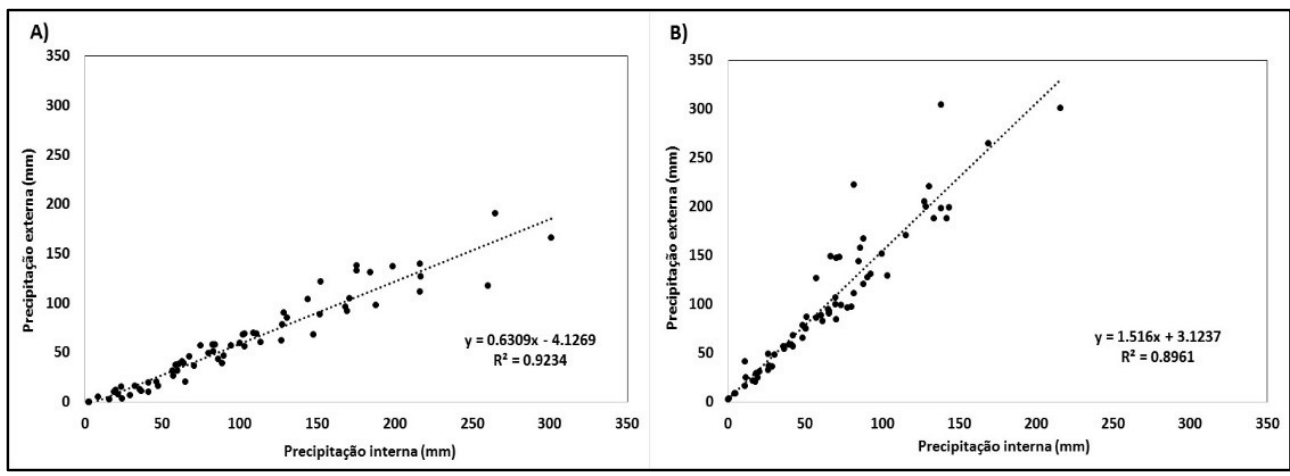

Figura 3: Regressão linear dos dados de precipitação externa e interna para a área de floresta nativa (A) e reflorestamento (B).

Na tabela 5 é apresentado o balanço hídrico no intervalo mensal, provindo de cálculos de dados diários. Observa-se de forma geral que a ETr obtida através do balanço hídrico foi menor em relação a ETp 
determinada pelo método de Penman-Monteith. Na área agrícola o método de Penman-Monteith superestimou a evapotranspiração em $572,4 \mathrm{~mm}$, ou seja, a ETp foi $26,0 \%$ maior em relação a ETr. Na floresta nativa a diferença foi de $20,1 \%$, ou $518,8 \mathrm{~mm}$, na pastagem foram $423,2 \mathrm{~mm}$ ou $18,6 \%$ e a menor diferença no reflorestamento, $386,7 \mathrm{~mm}$ ou $16,2 \%$ do total evapotranspirado.

Apesar de ser a menor diferença, os valores na área de reflorestamento ainda são muito elevados. Em um estudo sobre evapotranspiração regional nos EUA, Hobbins et al. (2001) observou que o método de Penman-Monteith subestimou a evapotranspiração em 7,9\% em comparação com a estimativa do balanço hídrico. Alencar et al. (2015) também observou uma superestimava da evapotranspiração diária pelo método de Penman-Monteith e atribui o resultado a velocidade do vento.

A altura do escoamento superficial médio, transformado em altura equivalente de água para a área da bacia hidrográfica foi de 102,3mm, correspondendo a 3,4\% da precipitação média. O maior escoamento superficial foi na agricultura com $116,7 \mathrm{~mm}$ representando $5,3 \%$ da precipitação anual, enquanto na floresta nativa o escoamento superficial foi de apenas 2,2\% da precipitação total. Segundo Ramos et al. (2014), áreas descobertas são suscetíveis a maiores alturas de escoamento, no entanto em áreas florestais, a vegetação, e em especial a serapilheira, é imprescindível na redução do escoamento superficial (CAMPOS et al., 2008). O armazenamento de água no solo teve baixa variação, tendo em vista os trabalhos de Vestena et al. (2007) e Collischonn et al. (2008), que explicam que a variação de armazenamento ao longo do tempo em uma bacia é muito baixa e pode ser até desprezada.

Com relação a porcentagem evapotranspirada, o método de Penman-Monteith variou entre $78,4 \%$ na área agrícola a 80,9\% na floresta nativa, ficando acima dos valores de ETp citados pela literatura. A evapotranspiração obtida pelo balanço hídrico mostrou os dados reais do total evapotranspirado, sendo o mais alto de $61,4 \%$ para a floresta nativa e o mais baixo de $52,4 \%$ para a agricultura. 0 maior volume de água na floresta é explicado pelo maior número de compartimentos, quando comparado com a agricultura, que é menos protegida e possui maior quantidade de água para processos de evaporação para a atmosfera. Resultados semelhantes foram encontrados por Kobiyama et al. (2008) em uma bacia hidrográfica da mesma região. Segundo Dias (2005), em florestas tropicais, a evapotranspiração é em torno de 50\% da precipitação anual.

Tabela 5: Balanço hídrico anual para os diferentes usos da terra (2013-2016), Lontras (SC).

\begin{tabular}{|l|c|c|c|c|c|c|c|c|}
\hline \multirow{2}{*}{ Variáveis } & \multicolumn{2}{c|}{ Agricultura } & \multicolumn{2}{c|}{ Floresta nativa } & \multicolumn{2}{c|}{ Pastagem } & \multicolumn{2}{c|}{ Reflorestamento } \\
\cline { 2 - 9 } & $\mathbf{m m}$ & $\mathbf{\%}$ & $\mathbf{m m}$ & $\mathbf{\%}$ & $\mathbf{m m}$ & $\mathbf{\%}$ & $\mathbf{m m}$ & $\mathbf{m}$ \\
\hline Precipitação & $2.213,7$ & $100 \%$ & $2.584,9$ & $100 \%$ & $2.279,2$ & $100 \%$ & $2.380,4$ & $100 \%$ \\
\hline Drenagem & 936,3 & $42,3 \%$ & 941,6 & $36,4 \%$ & 815,7 & $35,8 \%$ & 816,9 & $34,3 \%$ \\
\hline Escoamento superficial & 116,7 & $5,3 \%$ & 57,3 & $2,2 \%$ & 72,9 & $3,2 \%$ & 74,6 & $3,1 \%$ \\
\hline Armazenamento & 1,5 & $0,1 \%$ & 0,9 & $-0,04 \%$ & 1,1 & $0,05 \%$ & 1,7 & $0,1 \%$ \\
\hline Evapotranspiração real & $1.159,2$ & $52,4 \%$ & $1.571,6$ & $61,4 \%$ & $1.389,5$ & $61,0 \%$ & $1.487,2$ & $62,5 \%$ \\
\hline Evapotranspiração potencial & $1.735,6$ & $78,4 \%$ & $2.090,3$ & $80,9 \%$ & $1.812,7$ & $79,5 \%$ & $1.873,9$ & $78,7 \%$ \\
\hline Diferença (Etr x Etp) & 576,4 & $26,0 \%$ & 518,8 & $20,1 \%$ & 423,2 & $18,6 \%$ & 386,7 & $16,2 \%$ \\
\hline
\end{tabular}

Legenda: *ETr - evapotranspiração real; ETp - evapotranspiração potencial

A figura 4 mostra a comparação mensal entre a evapotranspiração potencial e real nos usos da terra estudados. Pode-se observar que a evapotranspiração calculada por Penman-Monteith superestimou a 
evapotranspiração ao decorrer do ano. Em todo os usos a maior diferença entre a ETp e ETr ocorreu no outono, na primavera e no verão.

No inverno a diferença foi a menor pois nesta estação existe uma menor influência da radiação, temperatura e da velocidade do vento, que são variáveis importantes na evaporação da água. Este resultado foi semelhante ao encontrado por Hallal et al. (2013), Muniz et al. (2014) e Cardoso et al. (2014). Em estudo da variabilidade intra e interanual da bacia hidrográfica em questão, Piazza et al. (2018) também encontrou valores de ETp maiores no verão (janeiro a março) e menores durante o inverno (junho a agosto).

A ETp apresentou pouca influência da precipitação, ou seja, a evapotranspiração por PenmanMonteith responde significativamente a radiação solar, a temperatura e ao vento, enquanto a ETr considera também a precipitação. Em termos gerais, observou-se que os maiores valores de evapotranspiração ocorreram no período de outubro a março, período de primavera/verão; e os menores nos meses de maio a julho que é o início do inverno, para ambos os métodos.

A maior diferença entre a ETp e a ETr ocorreu na área de floresta nativa, que foi de $848,1 \mathrm{~mm}(42,1 \%)$, seguido pelo reflorestamento com $654,1 \mathrm{~mm}(34,4 \%)$, pastagem com $524,3 \mathrm{~mm}(28,6 \%)$ e pela agricultura com 410,5mm (23,6\%). A diferença média foi de 32\% entre os métodos. Segundo Widmoser (2009), o método de Penman-Monteith pode apresentar erros de $30 \%$ quando comparados com dados de campo devido às incertezas associadas as variáveis de entrada.

$\mathrm{Na}$ agricultura (figura 4A) a ETp anual foi de $1.741,4 \mathrm{~mm}$ e a ETr de $1.330,9 \mathrm{~mm}$, com máxima de 173,6mm em março e mínima de $97,7 \mathrm{~mm}$ em junho. A ETr foi maior em janeiro (137,3mm) e menor em junho (72,2mm). Na floresta nativa (figura 4B) a ETp foi de 2.016,8mm, com máxima de $214,1 \mathrm{~mm}$ em março e mínima de $108,7 \mathrm{~mm}$ em junho. A ETr foi de $1.168,7 \mathrm{~mm}$ com máxima de $128,7 \mathrm{~mm}$ em fevereiro e mínima de 72,5 no mês de julho. Na área de pastagem (figura 4C) a ETp foi de $1.835,2 \mathrm{~mm}$, com máxima foi de 177,6mm em fevereiro e a mínima de $116,7 \mathrm{~mm}$ em junho. A ETr foi de $1.311,0 \mathrm{~mm}$, com máxima de 136,2mm em fevereiro e mínima de 75,8mm em julho.

No reflorestamento (figura 4D), a ETp média foi de 1.902,9mm, com máxima 197,7mm em fevereiro e mínima de 108,6mm em junho. A ETr foi de $1.248,7 \mathrm{~mm}$ como máxima de 135,1mm em fevereiro e mínima de 113,0 também no mês de junho. Barreto et al. (2009) também encontrou mais elevados de ETp por diferentes métodos nos meses de fevereiro e março e mais baixos paras os meses de junho e julho. Segundo Fietz et al. (2009) a ETp sofre maior influência da radiação solar no período de verão (dezembro a março) e menor no período de inverno (junho a setembro).

A figura 5 mostra os dados de ETr submetidos à análise de regressão linear com os dados da ETp em um intervalo de tempo decendial, considerando que este foi o intervalo de tempo que melhor se ajustou. A relação dos diferentes métodos foi parecida para todos os usos da terra, com maiores coeficientes de determinação $\left(R^{2}\right)$ nas áreas de agricultura e pastagem que tiveram como método de determinação os lisímetros volumétricos, que fornecem valores precisos de evapotranspiração através do balanço hídrico, também encontrado por Loss et al. (2007), Medeiros (2008) e Feltrin (2013). 


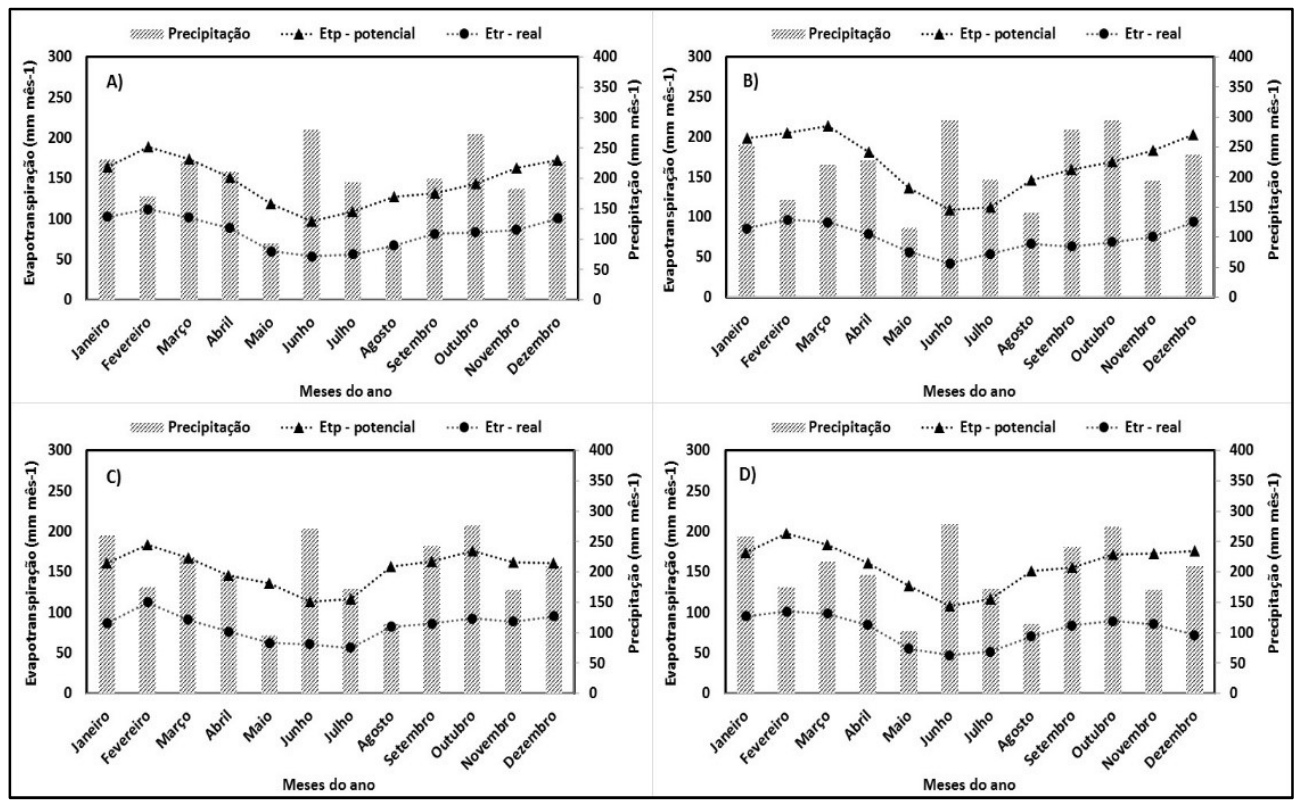

Figura 4: Comparação mensal entre a evapotranspiração potencial e real para a agricultura (A), floresta nativa (B), pastagem (C) e reflorestamento (D).

O uso de lisímetros volumétricos utilizados na determinação da $E \operatorname{Tr}$ demonstrou uma melhor eficiência do balanço hídrico. Mas os métodos alternativos utilizados na determinação da ETr para as áreas de floresta nativa e de reflorestamento também foram eficientes, com $R^{2}$ de 0,74 e 078 , respectivamente. Os fatores de correlação também estão próximos aos encontrados por López-Urrea et al. (2006) na comparação de valores de evapotranspiração determinados por lisímetros com o método de PenmanMonteith obteve um $\mathrm{R}^{2}$ de 0,91 .

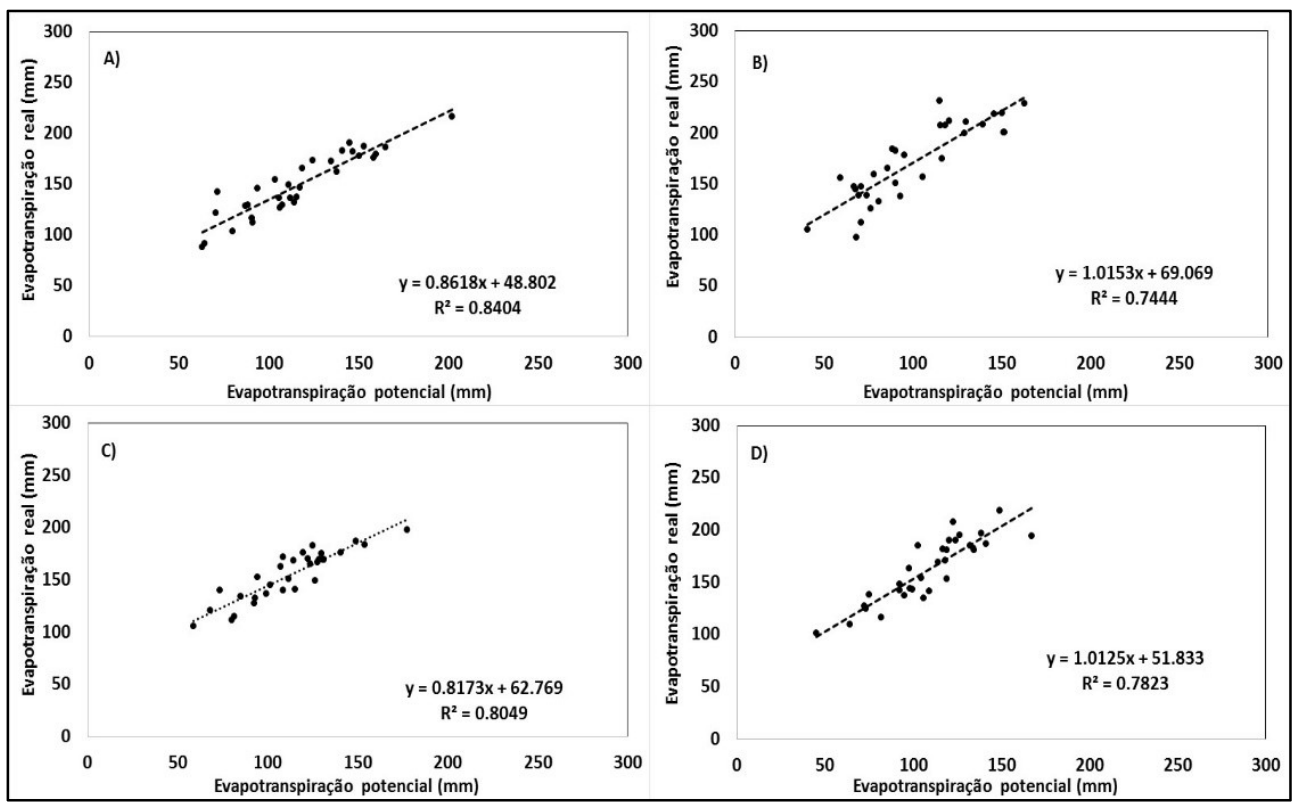

Figura 5: Relação entre ETp x ETr para agricultura (A), floresta nativa (B), pastagem (C) e reflorestamento (D).

\section{CONCLUSÕES}

A bacia hidrográfica do Ribeirão Concórdia apresentou uma distribuição irregular de precipitação, com chuvas superiores à média regional, resultado da forte influência das chuvas orográficas ocorridas na região. A cobertura florestal tem um importante papel dentro do balanço hídrico, como observado na 
interceptação. A floresta nativa interceptou $46,8 \%$ da precipitação e o reflorestamento $36,1 \%$. As chuvas de até $6,5 \mathrm{~mm}$ foram completamente interceptadas em áreas de floresta nativa, e no reflorestamento as chuvas de $2,1 \mathrm{~mm}$ ficam interceptadas.

Com os resultados, ficou claro que as mudanças de uso da terra, tais como agricultura, pastagem e reflorestamento causam alterações na dinâmica da água de uma bacia hidrográfica. O método de PenmanMonteith apontado pela FAO para a determinação da ETp apresenta valores diferentes das reais condições hídricas, pelo menos na bacia estudada, superestimando a ETp diária em todos os usos da terra estudados. Este comportamento pode estar atrelado a radiação solar e a temperatura do ar que são os fatores determinantes para a estimativa da evapotranspiração pelo método de Penman-Monteith.

O fato de os produtores rurais presentes na bacia ainda adotarem o sistema convencional de manejo do solo e das áreas agrícolas ficarem boa parte do ano descobertas, tem potencializado os processos erosivos e o aumento do escoamento superficial (5,3\% do total precipitado), enquanto que em áreas preservadas como a floresta nativa o escoamento é menor $(2,2 \%)$ devido as melhores condições físicas do solo. 0 método do balanço hídrico utilizado na determinação da ETr se mostrou mais eficiente quando comparado com o método padrão da ETp em um intervalo de tempo de 10 dias.

\section{REFERÊNCIAS}

ALENCAR, L. P.; SEDIYAMA, G. C.; MONTOVANI, E. C.. Estimativa da evapotranspiração de referência (ETo padrão FAO) para Minas Gerais na ausência de alguns dados climáticos. Engenharia Agrícola, Jaboticabal, v.35, n.1, p.3950, 2015. DOI: http://doi.org/10.1590/1809-4430

ALLEN, R. G.; PEREIRA, L. S.; RAES, D.; SMITH, M.. Crop evapotranpiration: guidelines of computing crop water requiriments. Roma: FAO, 1998.

ALMEIDA, A. C.; SOARES, J. V.. Comparação entre uso de água em plantações de Eucalyptus grandis e floresta ombrófila densa (Mata Atlântica) na costa leste do Brasil. Revista Árvore, Viçosa, v.27, n.2, p.159-170, 2003. DOI: http://doi.org/10.1590/S0100-67622003000200006

ALVES, R. F.; DIAS, H. C. T.; OLIVEIRA, J. C.; GARCIA, F. N. M.. Avaliação da precipitação efetiva de um fragmento de Mata Atlântica em diferentes estágios de regeneração no município de Viçosa, MG. Revista Ambiente \& Água, Taubaté, v.2, n.1, p.83-93, 2007. DOI: http://doi.org/10.4136/ambi-agua.21

ASCE-EWRI. Environmental and Water Resources Institute of the American Society of Civil Engineers. The ASCE Standardized reference evapotranspiration equation: report of the task committee on standardization of reference evapotranspiration. Reston: ASCE-EWRI, 2005.

BARRETO, C. E. A.; WENDLAND, E.; MARCUZZO, F. F. N.. Estimativa da evapotranspiração a partir de variação de nível estático de aquífero. Engenharia Agrícola, Jaboticabal, v.29, n.1, p.1-10, 2009. DOI: http://doi.org/10.1590/S0100$\underline{69162009000100006}$
BARROS, V. R.; SOUZA, A. P.; FONSECA, D. C.; SILVA, L. B. D. Avaliação da evapotranspiração de referência na Região de Seropédica, Rio de Janeiro, utilizando lisímetro de pesagem e modelos matemáticos. Revista Brasileira de Ciências Agrárias, Recife, v.4, n.2, p.198-203, 2009. DOI: http://doi.org/10.5039/agraria.v4i2a13

BERNARDO, S.; SOARES, A. A.; MANTOVANI, E. C.. Manual de irrigação. 8 ed. Viçosa: EDUFV, 2008.

CAMARGO, A. P.; CAMARGO, M. B. P.. Uma revisão analítica da evapotranspiração potencial. Bragantia, Campinas, v.59, n.2, p.125-137, 2000. DOI: http://doi.org/10.1590/S0006$\underline{87052000000200002}$

CAMPOS, E. H.; ALVES, R. R.; SERATO, D. S.; RODRIGUES, G. S. S. C.; RODRIGOS, S. C.. Acúmulo de serrapilheira em fragmentos de mata mesofítica e cerrado stricto senso em Uberlândia-MG. Sociedade \& Natureza, Uberlândia, v.20, n.1, p.189-203, 2008.

CARDOSO, G. M.; JUSTINO, F.. Simulação dos componentes da evapotranspiração sob condições climáticas atuais e de cenários climáticos futuros de aquecimento global com o uso de modelos de clima-vegetação. Revista Brasileira de Meteorologia, São Paulo, v.29, n.1, p.85-95, 2014. DOI: http://doi.org/10.1590/S0102-77862014000100009

CARVALHO, D. F.; SILVA, L. D.. Ciclo hidrológico o ciclo das águas. Volta Redonda: UNIFOA, 2006.

COLLISCHONN, W.; TASSI, R.. Introduzindo hidrologia. Porto Alegre: UFRGS, 2008.

CUARTAS, L. A.; TOMASELLA, J.; NOBRE, A. D.; HODNETT, M. G.; WATERLOO, M. J.; MÚNERA, J. C.. Interception water- 
partitioning dynamics for a pristine rainforest in Central Amazonia: marked differences between normal and dry years. Agricultural and Forest Meteorologyis, v.145, p.6983, 2007. DOI:

https://doi.org/10.1016/j.agrformet.2007.04.008

CUNHA, F. F.; MAGALHÃES, F. F.; CASTRO, M. A. Métodos para estimativa da evapotranspiração de referência para Chapadão do Sul-MS. Engenharia na Agricultura, Viçosa, v.21, n.2, p.159-172, 2013. DOI:

https://doi.org/10.13083/reveng.v21i2.346

DIAS, M. A. F. S.; COHEN, J. C. P.; GANDU, A. W.. Interações entre nuvens, chuvas e a biosfera na Amazônia. Acta Amazônica, v.35, n.2, p.215-22, 2005. DOI: http://doi.org/10.1590/S0044-59672005000200011

DIJK, A. I.; GASH, J. H.; GORSEL, E.; BLANKEN, P. D.; CESCATTI, A.; EMMEL, C.; GIELEN, B.; HARMAN, I. N.; KIELY, G.; MERBOLD, L.; MONTAGNANI, L.; MOORS, E.; SOTTOCORNOLA, M.; VARLAGIN, A.; WILLIAMS, C. A.; WOHLFAHRT, G.. Rainfall interception and the coupled surface water and energy balance. Agricultural and Forest Meteorology, v.214-215, p.402-415, 2015. DOI: https://doi.org/10.1016/j.agrformet.2015.09.006

DOORENBOS, J.; PRUITT, W. O.. Guidelines for predicting crop water requirements. Rome: FAO, 1977.

EMBRAPA. Empresa Brasileira de Pesquisa Agropecuária. Sistema Brasileiro de Classificação de Solos. Rio de Janeiro: EMBRAPA, 1999.

ESTEVES, B. S.; MENDONÇA, J. C.; SOUZA, E. F.; BERNARDO, S.. Avaliação do Kt para a estimativa da evapotranspiração (ETo) em Campos dos Goytacazes, RJ. Revista Brasileira de Engenharia Agrícola e Ambiental, Campina Grande, v.14, n.3, p.274-278, 2010. DOI: http://doi.org/10.1590/S1415$\underline{43662010000300006}$

FELTRIN, R. S.. Processos hidrológicos e balanço hídrico em lisímetros de drenagem em campo e mata nativa. Tese (Doutorado em Engenharia de Água e Solo) - Universidade de Santa Maria, Santa Maria, 2013.

FIETZ, C. R.; FISCH, G. F.. Avaliação de modelos de estimativa do saldo de radiação e do método de Priestley-Taylor para a região de Dourados, MS. Revista Brasileira de Engenharia Agrícola e Ambiental, Campina Grande, v.13, n.4, p.449-453, 2009. DOI: http://doi.org/10.1590/S141543662009000400012

GARCIA, M., RAES, D.; ALLEN, R.; HERBAS, C.. Dynamics of reference evapotranspiration in the Bolivian highlands (Altiplano). Agricultural Forest and Meteorology, v.125, p.67-82, 2004. DOI:

https://doi.org/10.1016/i.agrformet.2004.03.005

GEBLER, S.; FRANSSEN, H. J. H.; PÜTZ, T.; POST, H.; SCHMIDT, M.; VEREECKEN, H.. Actual evapotranspiration and precipitation measured by lysimeters: a comparison with eddy covariance and tipping bucket. Hydrology and Earth System Sciences, v.19, p.2145-2161, 2015. DOI: https://doi.org/10.5194/hess-19-2145-2015

GOULDEN, M. L.; LITVAK, M.; MILLER, S. D.. Factors that control Typha marsh evapotranspiration Aquatic. Botany, v.86, p.97-106, 2007. DOI:

http://doi.org/10.1016/i.aquabot.2006.09.005

HALLAL, M. O. C.; SCHOFFEL, E. R.; BRIXNER, G. F.; RADUNS, A. L.. Estimativa da evapotranspiração de referência e sua relação com a precipitação ocorrida na região de Pelotas-RS. Irriga, Botucatu, v.18, n.1, p.85-98, 2013. DOI: http://doi.org/10.15809/irriga.2013v18n1p85

HARGREAVES, G. H.. World water for agriculture. Washington: Utah State University, 1977.

HENRIQUE, F. A. N.; DANTAS, R. T.. Estimativa da evapotranspiração de referência em Campina Grande, Paraíba. Revista Brasileira de Engenharia Agrícola e Ambiental, Campina Grande, v.11, p.594-599, 2007. DOI: http://doi.org/10.1590/S1415-43662007000600007

HILLEL, D.; KRENTOS, V. D.; STYLIANOU, Y.. Procedure and test of an internal drainage method for measuring soil hydraulic characteristics in situ. Soil Science, n.114, p.395400, 1972.

HOBBINS, M. T.; RAMIREZ, J. A.; BROWN, T. C.. The complementary relationship in estimation of regional evapotranpiration: An enhanced advective-aridity model. Water Resources Research, v.37, n.5, p.1389-1403, 2001. DOI: https://doi.org/10.1029/2000WR900359

KOBIYAMA, M.; CHAFFE, P. L. B.. Water balance in CubatãoSul river catchment, Santa Catarina, Brazil. Revista Ambiente e Água, Taubaté, v.3, p.5-17, 2008. DOI: http://doi.org/10.4136/1980-993X

LANE, P. N. J.; MORRIS, J.; NINGNAN, Z.; GUANGYI, Z.; GUOYI, Z.; DAPING, X.. Water balance of tropical eucalypt plantations in south-eastern China. Agricultural and Forest Meteorology, v.124, n.3-4, p.253-267, 2004. DOI: http://doi.org/0.1016/j.agrformet.2004.01.015

LIBARDI, P. L.. Dinâmica da água no solo. São Paulo: EDUSP, 2005.

LIMA, J. R. S.; ANTONINO, A. C. D.; SOARES, W. A.; SOUZA, E. S.; LIRA, C. A. B. O.. Balanço hídrico no solo cultivado com feijão-caupi. Revista Brasileira de Ciências Agrárias, Recife, v.1, p.89-95, 2006. DOI

http://doi.org/10.5039/agraria.v1i1a141

LIMA, W. P.. Hidrologia florestal aplicada ao manejo de bacias hidrográficas. 2 ed. São Paulo: 2008.

LIVESLEY, S. J.; BAUDINETTE, B.; GLOVER, D.. Rainfall interception and stemflow by eucalypt street trees-The impacts of canopy density and bark type. Urban Forestry Urban Greening, v.13, n.1, p.192-197, 2014. DOI: http://doi.org/10.1016/i.ufug.2013.09.001

LOOS, C.; GAYLER, S.; PRIESACK, E.. Assessment of water balance simulations for large-scale weighing lysimeters. Journal of hidrology, v.335, n.4, p.259-270, 2007. DOI: http://doi.org/10.1016/j.jhydrol.2006.11.017

LÓPEZ-URREA, R.; OLALLA, F. M. S.; FABEIRO, C.; MORATALLA, A.. Testing evapotranspiration equations using Iysimeter observations in a semiarid climate. Agricultural 
Water Management, v.85, n.1-2, p.15-26, 2006. DOI: https://doi.org/10.1016/i.agwat.2006.03.014

LU, N.; CHEN, S.; WILSKE, B.; SUN, G.; CHEN, J..

Evapotranspiration and soil water relationships in a range of disturbed and undisturbed ecosystems in the semi-arid Inner Mongolia, China. Journal of Plant Ecology, v.4, p.49-60, 2011. DOI: https://doi.org/10.1093/jpe/rtq03

MEDEIROS, P. V.. Análise da evapotranspiração de referência a partir de medidas lisimétricas e ajuste estatístico de estimativas de nove equações empírico teóricas com base na equação de Penman-Monteith. Dissertação (Mestrado em Engenharia Civil) - Universidade de São Paulo, São Carlos, 2008.

MOTA, F. S.; AGENDES, M. O. O.; SOUZA, L. K.. Estimativa da evapotranspiração de referência nos principais tipos de climas do Brasil com instrumentos de baixo custo. Revista Brasileira de Meteorologia, São Paulo, v.6, n.1, p.479-486, 1991.

MOURA, A. E. S. S.; CORREA, M. M.; SILVA, E. R.; FERREIRA R. L. C.; FIGUEIREDO, A. C.; POSSAS, J. M. C.. Interceptação das chuvas em um fragmento de floresta da mata atlântica na bacia do Prata, Recife, PE. Revista Árvore, Viçosa, v.33, n.3, p.461-469, 2009. DOI: http://doi.org/10.1590/S010067622009000300008

MOURA, A. E. S. S.; CORREA, M. M.; SILVA, E. R.; LIMA, G. S.; SENA, J. R.; FIGUEIRÊDO, A. C.. Precipitação efetiva nos períodos chuvoso e pouco chuvoso em um fragmento de Mata Atlântica, Recife -PE. Revista brasileira de Recursos Hídricos, Porto Alegre, v.17, n.7, p.7-16, 2012. DOI: http://doi.org/10.21168/rbrh.v17n4.p7-16

MUNIZ, R. A.; SOOUZA, E. F.; MENDONÇA, J. C.; ESTEVES, B. S.; LIUSADA, L. L.. Balanço de energia e evapotranspiração do capim Moçamba sob sistema de pastejo rotacionado. Revista Brasileira de Meteorologia, São Paulo, v.29, n.1, p.47-54, 2014. DOI: http://doi.org/10.1590/S0102$\underline{77862014000100005}$

OLIVEIRA, L. M. M.; MONTENEGRO, S. M. L.; AZEVEDO, J. R. G.; SANTOS, F. X.. Avaliação da evapotranspiração de referência (ETo) na bacia experimental do riacho Gameleira$\mathrm{PE}$, utilizando lisímetro de pesagem hidráulica e métodos indiretos. Revista Brasileira de Ciências Agrárias, Recife, v.3, n.1, p.58-67, 2008. DOI:

http://doi.org/10.5039/agraria.v3i1a250

PAIGE, G. B; HILLEL, D.. Comparison of three methods for assessing soil hydraulic properties. Soil Science, n.155, p.175-189, 1993. DOI: http://doi.org/10.1097/00010694$\underline{199303000-00003}$

PAULHUS, J. L. H.; KOHLER, M. A.. Interpolation of missing precipitation records. Monthly Weather Review, v.80, n.8, p.129-133, 1056, 1952. DOI: https://doi.org/10.1175/15200493(1952)080<0129:IOMPR>2.0.CO;2

PENMAN, H. L.. Natural evaporation from open water, bare soil, and grass. Proceedings of the Royal Society, v.193, n.1, p.20-146, 1948. DOI: http://doi.org/10.1098/rspa.1948.0037

PEREIRA, A. R.; NOVA, N. A. V.; SEDIYAMA, G. C.. Evapotranspiração. Piracicaba: FEALQ, 1997.
PEREIRA, C. R.; VALCARCEL, R.; BARBOSA, R. S. Quantificação da chuva oculta na Serra do Mar, estado do Rio de Janeiro. Ciência Florestal, Santa Maria, v.26, n.4, p.1061-1073, 2016. DOI: http://doi.org/10.5902/1980509824995

PIAZZA, G. A.; PINHEIRO, A.; KAUFMANN, V.; TORRES, E.; VENZON, P. T.; GOTARDO, R.; BAPTISTA, G. C. Z.; KNAESEL, K. M.. Histerese intranual das variáveis hidroclimáticas da Bacia do Ribeirão Concórdia, Santa Catarina, Sul do Brasil. In: SIMPÓSIO BRASILEIRO DE RECURSOS HÍDRICOS, 20. Anais. Florianópolis: UFSC, 2017.

PRIESTLEY, C. H. B; TAYLOR, R. J.. On the assessment of surface heart flux and evaporation using large-scale parameters. Monthly Weather Review, v.100, n.2, p.81-92, 1972. DOI: https://doi.org/10.1175/15200493(1972)100<0081:OTAOSH>2.3.CO;2

RAMOS, J. C.; BERTOL, I.; BARBOSA, F. T.; MAROTI, J.; WERNER, R. S.. Influência das condições de superfície e do cultivo do solo na erosão hídrica em um Cambissolo Húmico. Revista Brasileira de Ciência do Solo, Viçosa, n.38, p.15871600, 2014. DOI: http://doi.org/10.1590/S010006832014000500024

RANDOW, C.; MANZI, A. O.; KRUIJT, B.; OLIVEIRA, P. J.; ZANCHI, F. B.; SILVA, R. L.; HODNETT, M. G.; GASH, J. H. C.; ELBERS, J. A.; WATERLOO, M. J.; CARDOSO, F. L.; KABAT, P.. Comparative measurements and seasonal variations in energy and carbon exchange over forest and pasture in South West Amazonia. Theoretical and Applied Climatology, v.78, p.5-26, 2004. DOI: http://doi.org/10.1007/s00704-004$\underline{0041-z}$

REICHARDT, K; TIMM, L. C.. Solo, Planta e atmosfera: Conceitos, processos e aplicações. Barueri: Manole, 2004.

RODRIGUES, G. D. S.; SOUZA, L. S. B.; MOURA, M. S. B.; SILVA, T. G. F.. Refletância das culturas do milho e feijãocaupi em sistemas de plantio exclusivo e consorciado. In: JORNADA DE INICIAÇÃO CIENTÍFICA DA EMBRAPA SEMIÁRIDO, 7. Anais. Petrolina: EMBRAPA, 2012.

SARI, V.; PAIVA, E. M. C. D.; PAIVA, J. B. D.. Interceptação da chuva em diferentes formações florestais na região sul do Brasil. Revista Brasileira de Recursos Hídricos, Porto Alegre, v. 21 n.1, p.65-79, 2016. DOI:

http://doi.org/10.21168/rbrh.v21n1.p65-79

SCHRADER, F.; DUNER, W.; FANK, J.; GEBLER, S.; PUTZ, T.; HANNES, M.; WOLLSCHLAGER, U.. Estimating precipitation and actual evapotranspiration from precision lysimeter measurements. SciVerse Science Direct, v.19, p.543-552, 2013. DOI: https://doi.org/10.1016/j.proenv.2013.06.061

SILVA, A. M. A.; OLIVEIRA, A. G.; LOEZER, T. L.; SOUZA, R. M. Avaliação do comportamento da precipitação entre $o$ primeiro planalto paranaense e o litoral do Paraná no ano hidrológico 2010/2011. Revista Geonorte, Manaus, v.2, n.5, p.967-974, 2012.

SOUZA, A. P.; CARVALHO, D. F.; SILVA, L. B. D.; ALMEIDA, F. T.; ROCHA, H. S.. Estimativas da evapotranspiração de referência em diferentes condições de nebulosidade. Pesquisa Agropecuária Brasileira, Brasília, v.46, p.219-228, 
2011. DOI: http://doi.org/10.1590/S0100$\underline{204 \times 2011000300001}$

SOUZA, A. S. P.. Avaliação de métodos de estimativa da evapotranspiração de referência para fins de manejo de irrigação. Dissertação (Mestrado em Meteorologia) Universidade Federal do Rio de Janeiro, Rio de Janeiro, 2011.

TASUMI, M.; ALLEN, R. G.; TREZZA, R.. At-surface reflectance and Albedo from satellite for operational calculation of land surface energy balance. Journal of Hydrologic Engineering, v.13, p.51-63, 2008. DOI:

https://doi.org/10.1061/(ASCE)1084-0699(2008)13:2(51)

THOMAZ, E. L.. Avaliação de interceptação e precipitação interna em capoeira e Floresta secundária em GuarapuavaPR. Geografia, Londrina, v. 14, n. 1, p. 47-60, 2005. DOI: http://doi.org/10.5433/2447-1747.2005v14n1p47

THORNTHWAITE, C. W.. An approach towards a rational classification of climate. Geographycal Review, London, v.38, n. 1, p.55-94, 1948.

UNLU, M.; KAPUR, B.. Comparison of soybean evapotranspiration measured by weighing lysimeter and Bowen ratio-energy balance methods. African Journal of Biotechnology, v.9, n.30, p.4700-4713, 2010.
UNOLD, G.; FANK, J.. Modular design of field lysimeters for specific application needs. Water Air Soil Pollution, v.8, p.233-242, 2008. DOI: http://doi.org/10.1007/s11267-0079172-4

VEPRASKAS, M. J.; HUFFMAN, R. L.; KREISER, G. S.. Hydrologic models for altered landscapes. Geoderma, v.131, n.3, p.287-298, 2006. DOI:

https://doi.org/10.1016/i.geoderma.2005.03.010

VESTENA, L. R.; KOBIYAMA, M.. Water Balance in Karst: case study of the ribeirão da Onça Catchment in Colombo City, Paraná State - Brazil. Brazilian Archives of Biology and Technology an International Journal, v.50, n.5, p.905-912, 2007. DOI: http://doi.org/10.1590/S151689132007000500020

WIDMOSER, P.. A discussion on and alternative to the Penman-Monteith equation. Agricultural Water Management, v.96, n.4, p.711-721, 2009. DOI: https://doi.org/10.1016/i.agwat.2008.10.003

WISCHMEIER, W. H.; SMITH, D. D.. Predicting rainfall erosion losses: a guide to conservation planning. Washington: United States Department of Agriculture, 1978.

A CBPC - Companhia Brasileira de Produção Científica (CNPJ: 11.221.422/0001-03) detém os direitos materiais desta publicação. Os direitos referem-se à publicação do trabalho em qualquer parte do mundo, incluindo os direitos às renovações, expansões e disseminações da contribuição, bem como outros direitos subsidiários. Todos os trabalhos publicados eletronicamente poderão posteriormente ser publicados em coletâneas impressas sob coordenação da Sustenere Publishing, da Companhia Brasileira de Produção Científica e seus parceiros autorizados. Os (as) autores (as) preservam os direitos autorais, mas não têm permissão para a publicação da contribuição em outro meio, impresso ou digital, em português ou em tradução. 